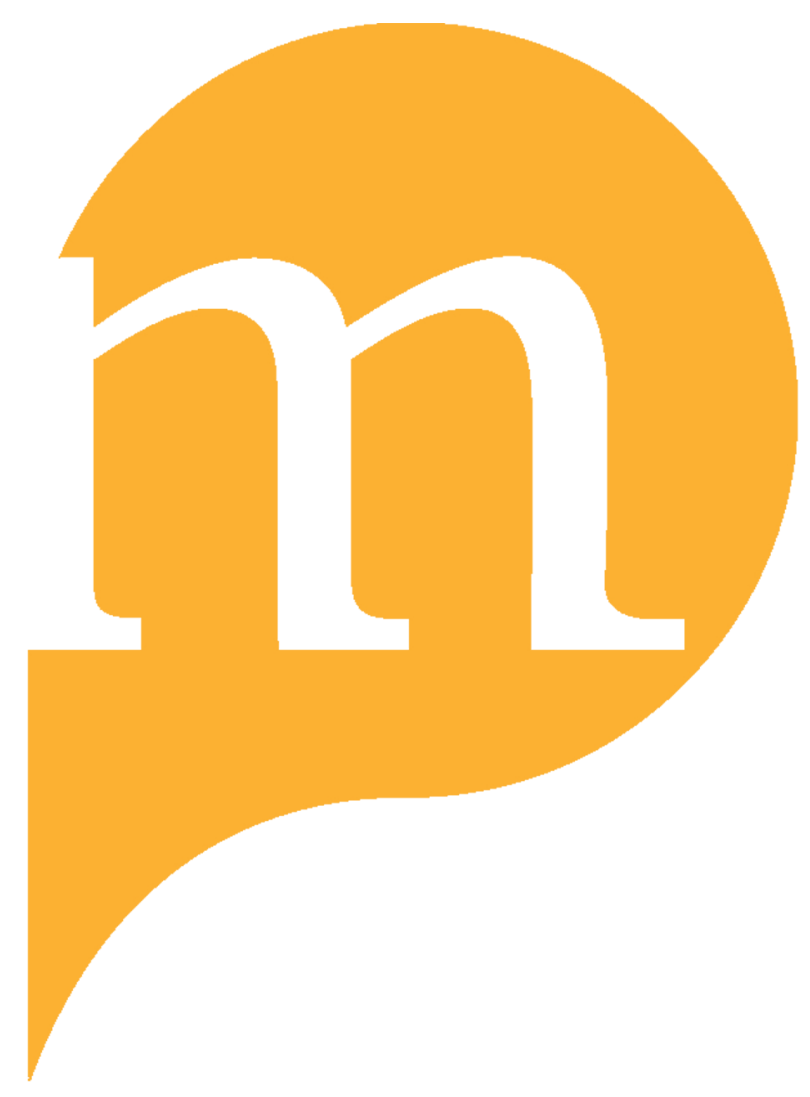

PROJECT MUSE 


\section{Making Mas: \\ TruDynasty Carnival \\ Takes Josephine Baker \\ to the Caribbean \\ Carnival}

Jacqueline Taucar

Toronto's annual Scotiabank Caribbean Carnival Festival ${ }^{1}$ draws over a million spectators to watch groups of masqueraders (Mas bands), in elaborate costumes called "Mas," ${ }^{2}$ create a kinesthetic landscape of colour as they parade along Lake Shore Boulevard. Yet Canadian scholarship of Caribbean Carnival has overlooked the design and performance of Mas. Many Caribbean Carnival scholars approach their study from sociology, politics, geography, or diaspora studies perspectives, focusing upon discursive understandings of bodies, space, and race. For example, Jackson and Gallaugher examine how festival space is constructed both physically and symbolically within Toronto and shed light upon the continued marginalization of the Black community within the political landscape. Foster, Walcott, and NourbeSe Philip write about the role of Caribbean Carnival in the performance of Blackness in Canada, while Phillip, Espinet, and Premdas explore the Caribbean diasporic identity. Although community newspapers such as Caribbean Camera, Share, or Scarborough Mirror occasionally publish articles about Mas band leaders and designers, no scholarly publications examine the design or aesthetics of Mas costumes in Toronto's Caribbean Carnival. ${ }^{3}$ Despite the importance of costumes to carnival, being that the very essence of Caribbean-style carnival is to "play mas," the material and aesthetic elements are often disregarded. As a performance studies scholar rooted in theatre, I recognize (to borrow and adapt from J. L. Austen) that humans not only do things with words, but also do things with their bodies and with material objects. By focusing upon the costume as the subject of study, we can begin to evaluate and connect to the critical discourses surrounding Caribbean Carnival from another perspective that foregrounds the interconnectedness of objects to ideas and social practices.

Having never designed or performed Mas, I credit Thea Jackson, Mas designer and band leader of TruDynasty Carnival, and her partner, Dario Jackson, as my collaborators in this article. Our interview on 20 January 2012 opened a window into a process that is

$$
\text { Jacqueline taucar / C C C } 152 \text { fall } 2012
$$


largely absent from the archive, and I have come to appreciate that designing Mas for a band is an enormous enterprise. ${ }^{5}$ To explore all elements of designing Mas in depth is beyond the scope of this work. Rather, I will focus on the design, construction, and performance of TruDynasty's 2011 Queen costume, "Josephine Dancing at the Market" (hereafter "Josephine”). First, I will explore how, in designing "Josephine," Jackson worked with Mas designer and creator Ross Stone to find a way to reimagine the historical figure Josephine Baker as a carnival costume.

\section{Designing Mas}

For TruDynasty's second year, Jackson selected “The Roaring Twenties" as the theme for the band to portray in 2011. The design process began with researching the fashion, music, art, and iconic figures of the era and selecting elements of the 1920s to represent sections of their band. Growing up, Jackson's mother was a key figure in educating her about Black history and the impact Baker had during the 1920s. Baker broke the colour barrier in entertainment to become a famous singer and dancer, become the first African American film star, and lead the movement to integrate the American concert hall. Baker's legacy inspired Jackson: "I thought that she was the most important factor of all the sections that we did. She was the stand out [element] of [the era]. So I wanted to model the Queen after her" (Jackson and Jackson interview). Jackson and Stone developed a design that negotiated a connection to Baker in an identifiable manner for Toronto's Carnival audiences. Stone sketched two different concepts for a Queen costume to pay tribute to Baker's dancer persona: "Josephine Dancing in the Moonlight" and "Josephine Dancing in the Market” (Jackson and Jackson interview). Immediately, Jackson was drawn to the second idea. Placing Baker within the marketplace setting allows audience members a way in to understanding and identifying with Baker. Co-band leader Dario Jackson explains,

For the Caribbean people in Canada, there's no real connection for them to the "Roaring Twenties," so we said let's do something that the average Caribbean person would do, which is going to the market. The market is [a daily activity,] something that the average Caribbean person could relate to. [Caribbean] people like to dance, they can relate to the market, the fish, the fruit. (Jackson and Jackson interview)

In the Caribbean, the market is a social and cultural institution, as food culture scholar Lynne Marie Houston argues: "Markets are often social gathering places to gossip or share news" (77). In the Caribbean diaspora, like Canada, Caribbean grocery stores are established to cater to expatriate communities. "Josephine" reimagines Baker not as a primitive African, as she is so often iconically portrayed in photographs and posters, but within the realm of the Caribbean marketplace, a familiar place for the Caribbean people of Toronto.

\section{Constructing Mas}

To build the "Josephine" Mas, Stone, the designer, begins with the base, a welded three-wheeled frame upon which the entire costume is constructed. The weight of the costume, which can weigh up to two to three times the weight of the performer (McKeown, "King \& Queen") and reach heights over ten metres, is supported by the three-wheeled frame, making the costume easier to move in the King and Queen competition and in the parade. ${ }^{6}$ Jackson emphasizes the importance of the frame, balance, and aerodynamics of a costume: "The frame is the important thing, because that is what is holding up everything. If that is unstable then your whole costume will collapse....... the slightest bit of wind can blow your costume over or it can make it unstable" (Jackson and Jackson interview). Giving "Josephine" its height and width, the frame has several spokes upon which long metal and fibreglass rods protrude out vertically and outwards in a fan-like shape. Wire, decorated with glitter to reflect the light, connects the rods to each other, foregrounding the central focus of the costume, an aestheticized bent-wire version of Josephine Baker. Wire bending is the heart of constructing big Mas costumes in Caribbean-style carnivals. Like a skeleton, the wire structure provides the supporting structure for decoration with feathers, fabric, sequins, and beading.

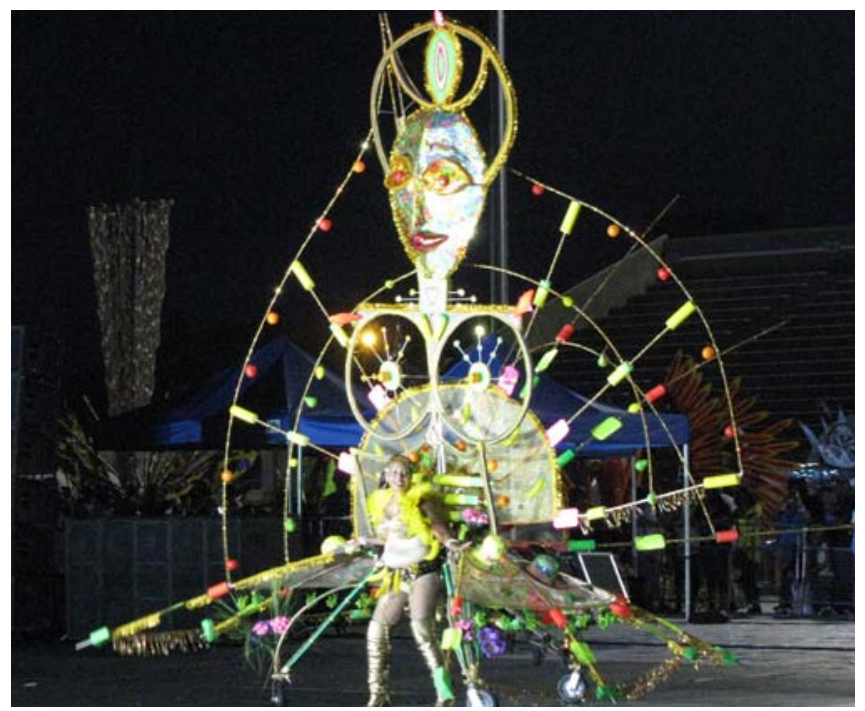

The follow spotlights catch the glitter and the structure of "Josephine" at the adjudication, 28 July 2011.

Photo by Shawn and Kara King (http://karabana.blogspot.ca/)

TruDynasty's “Josephine” Mas hybridizes iconic elements of Baker's imagery with elements of the Caribbean marketplace, creating a new understanding of Baker's body for Caribbean Carnival. The principle focus of the costume is Josephine Baker, an almost seven-metre bent-wire figure with a metallic bronze mask-like face and sculptural breasts. The bronzed mask can be read as a citation of Baker's status as the "Bronze Venus," the seductive and exotic African American entertainer who captured the imaginations of Parisians. On the costume, the most prominent sign of Baker's image is 


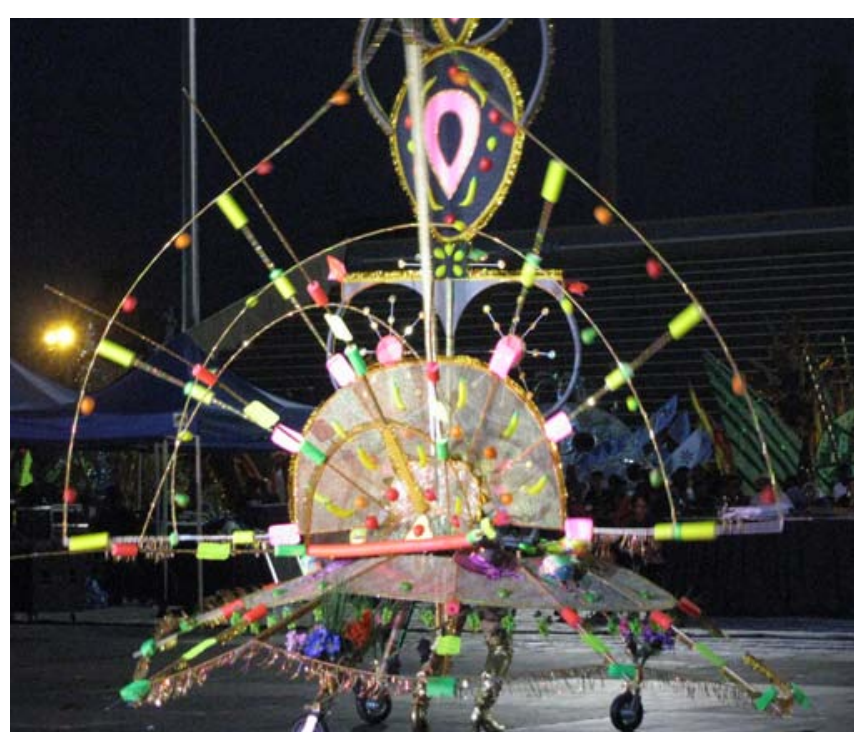

Dancing the Mas: in less than five minutes the performer must showcase the costume. Seen here: a view of the back of the Josephine Mas. Photo by Shawn and Kara King (http://karabana.blogspot.ca/)

the near two-metre-wide pair of breasts sculpted from bent wire, acknowledging an iconography that is dominated by nakedness and primitive imagery that itself is premised on racist stereotypes and objectifications of the Black body. Born on 3 June 1906 in St. Louis, Missouri, Baker never saw Africa and had no knowledge of tribal cultures and/or dance forms, yet in her audience's gaze she was transformed into the primitive through her danse sauvage where she performed nude, except for feathers around her thighs. The exhibition of Baker's body shares resonances with the "Hottentot Venus," Saartjie Baartman, who was exhibited in the nineteenth century for her racialized exoticism and erotic features, her buttocks and genitalia. In both cases, the display of the exotic - an imagined construct of a male-oriented, colonizing gaze-represents the relationship between "otherness" and Eurocentric civilization, supporting the notions of Empire and official culture of colonialism. Baartman, unlike Baker, lacked the agency and freedom over her display and was exploited until her death in 1815. Baker used and parodied the racial stereotyping of the "primitive" to achieve unparalleled success and agency on the Parisian stage and society at a time when Black females had very little of either. The carnivalesque breasts of the "Josephine" Mas extend upwards and outwards, beyond the natural boundaries of the body. Grotesquely exaggerated in a Bakhtinian sense, the breasts are not only a parody of Baker's image, but also a celebration of the spectacle of nudity, its bodily excesses and its pleasures. In doing so, the Mas acknowledges the historical discourse of the primitive body surrounding Baker while opening up other ways of understanding the body within carnival.

Using elements from a Caribbean market, "Josephine" translates Baker's image from exotic female entertainer to a local West Indian woman shopping, or selling, in marketplace. On "Josephine," mesh-like netting is used predominantly lower
Grotesquely exaggerated in a Bakhtinian sense, the breasts are not only a parody of Baker's image, but also a celebration of the spectacle of nudity, its bodily excesses and its pleasures.

to the ground to cover the three-wheeled base, resembling a skirt for the large figure of Baker on the costume. The skirt is decorated with piles of colourful straw hats; tropical fruit like pineapples, watermelon, and citrus; and flowers. Oranges and limes also hang from the wires and rods that extend up and out from the base of the costume. Although Baker's success has been directly associated with her "nakedness," Anne Cheng notes, Baker's skin "is a remarkably layered construct" often associated with sartorial elements like bananas, feathers, and drapery (7). Bananas figure prominently on the costume in two different places: first, bananas are placed on the meshlike fabric constructed in a fan shape above the base of the Mas costume; and second, around the Mas performer's waist piece, a citation of Baker's banana skirt from her "Banana Dance." Aside from the racial and erotic undertones, the bananas also gesture to local colonial politics and economics in the Caribbean as "banana plantations were being promoted as a supplement to and replacement for the sugar plantations" in the 1920s (Cheng 45). With all its market elements, the costume evokes the image of a higgler, a woman who sells food at the market or in the street, walking house to house with her wares. Higglers represent "a powerful image in Afro-Caribbean history, a woman who symbolizes local economic ingenuity and female independence" (Freeman 1019), qualities that Baker also possessed. The costume actively rewrites history and shifts Baker's position from exotic to familiar, illustrating the possibility of destabilizing fixed interpretations of Baker's identity as a primitive savage to be tamed and opening up ways of viewing Baker from a Canadian Caribbean perspective.

\section{Performing Mas at the King and Queen Competition}

Mas is more than just the costume alone. Rather, it becomes Mas through performance, as Ferris and Thompsett contend, "when the player plays it, connecting to its meaning from inside him/herself and giving that character or thematic aspect full life on the street" (47). At the King and Queen competition in Toronto's Caribbean Carnival, Big Mas costumes are adjudicated on two sets of criteria that are related: first, the Mas is evaluated for visual impact, thematic representation, and costume details; and, second, costumes are evaluated on the performer's ability to dance and interpret the Mas. In less than five minutes, the performer showcases the costume for the judges by "dancing the Mas" to music, requiring practice and an understanding of the costume's physics. Because of the size and the width of most Kings and Queens' costumes, 


\begin{tabular}{c}
\hline Jackson: your body \\
wants to move on beat \\
with the music, but \\
[parts of the costume] \\
are moving just a little \\
bit slower than your \\
movements ... you have \\
to remember that you \\
are dancing the Mas ... \\
\hline
\end{tabular}

performers cannot make sharp, 360-degree turns. Rather, the Mas is danced in large figure-eight patterns and circles in front of the judges and audiences, displaying the colours and the details of the costume. Floodlights and follow spots emphasize the movement qualities of the Mas by reflecting the decorative details of metallic foils, sequins, beads, and glitter, adding to the visual effect. When showcasing the costume from a fixed spot, the performer must exaggerate side-to-side movements to transfer enough energy to produce movement at the extremities of the structure. Because the Mas is so large and heavy, dancing with the music is a challenge and physically demanding. As Jackson explains, "your body wants to move on beat with the music, but [parts of the costume] are moving just a little bit slower than your movements" (Jackson and Jackson interview). There is a slight delay in the responsiveness of the costume to the performer's movements, so "you have to remember that you are dancing the Mas, not [yourself]" (Jackson and Jackson interview).

The performance of "Josephine" cites Baker's infamous "Banana Dance" performed in 1927 at the Folies Bergère, Paris. In the dance, with what one critic called "remarkable humour" (André Rouverge qtd in Dalton and Gates 918), Baker animates bananas encircling her waist by twirling her hips, undulating her torso, and shaking her buttocks, both enthralling and disgusting Parisians. Whereas Baartman's passive body, a century prior, became a surface upon which Europeans constructed Black female sexuality, Baker activated the body to return the audience's gaze. Indeed, Baker played into the audience's racialized - and sexualized - conceptions of the Black female body, but did so with parody and satire, often crossing her eyes, pulling faces, and protruding her bottom in a playful "moon" to her audience. "Josephine" enacts Baker's playfulness and character in two ways. First, the performer dancing the Mas is costumed in a manner consistent with the theme: she wears a banana belt that bounces with her circular hip movements popularly known as "wining" by Caribbean peoples. Second, the way in which the performer dances the Mas brings to life Baker's character. The wires and thirty-footlong rods that extend vertically supporting the wire-sculpted Baker are a combination of metal and light-weight fibreglass that responds to the performer's movement. As the performer dances sharply from side to side, the Baker sculpture appears to sway and gyrate wildly as if she, too, is dancing. The enormous wire-frame breasts bounce and shimmy with the music, uncannily resembling eyes that confront the audience's gaze. The back of the costume, shaped like a half "moon" covered in a golden mesh or netting, gyrates and shakes at the audience and judges. The carnivalesque breasts and rear end can be read as a critical intervention into the racialized stereotypes of a hyper-sexualized Black femininity, whose exaggeration exposes such discourse as absurdity.

While costume and the performance "bare" the traces of historical readings of Baker's body as the "exotic primitive," the costume's market elements shift the perspective towards a more local and familiar understanding for Caribbean people in Toronto. Unlike Baker, who danced for white Europeans with a colonizing gaze, "Josephine" dances for a Toronto audience predominantly from the Caribbean diaspora. The change in audience shifts the intent of the gaze. Rather than find exoticism and primitivism, Toronto's audiences see the familiar: the market of the Caribbean, the song and dance of Caribbean culture, and the carnival license to enjoy and celebrate the body - especially the female body. As both the performer and the Mas wine and dance, I see the discourse shifting towards how women reposition their bodies within carnival to assert their pleasure in their bodies and sexuality. 


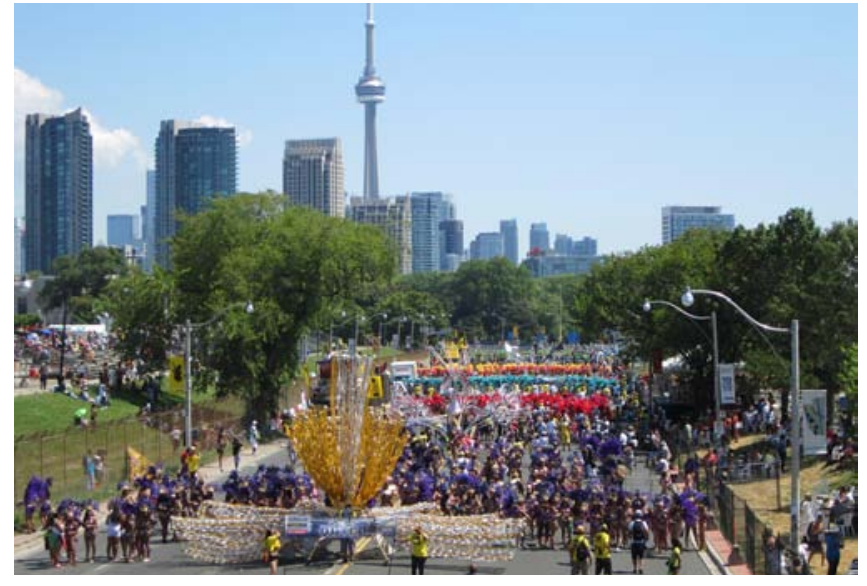

Scotiabank Caribbean Carnival Festival Parade. 27 July 2011.

Photo by Jacquey Taucar

While cultural conditions can proscribe women's sexuality and its expression, because the patriarchy defines the terms of being sexual, Judith Bettelheim contends that the female masquerader can use her sexuality to become an active agent (69). M. NourbeSe Philip writes about the empowerment women can experience as they play Mas during carnival: "Oh, for a race of women! - shaking their booty, doin their thing, their very own thing, jazzin it up, winin up and down the streets, parading their sexuality for two (w)hole daystaking back the streets making them their own" (107). In performance, "Josephine" actively claims space and female sexuality represented by breasts and buttocks, thereby denying their objectification. As such, "Josephine" avoids reifying and fixing understandings of Baker's body, but rather opens the discourse to multiple and "other" interpretations.

\section{Conclusion}

Mas, or masquerade, is in itself neither a character nor a costume, but the combination of the two, given life by the player on the road. - Tompsett

TruDynasty's Queen Mas, "Josephine Dancing at the Market," creates a performative palimpsest that negotiates and shifts between both the historical and discursive understandings of Josephine Baker and the strategically reimagined Caribbeaninspired persona. Traces of Baker's iconicity are present in the design and the performance, notably in the representation of female sexuality, the breasts and buttocks, as well as the racialized undertones inherent in the bananas. Jackson's Caribbean reimagining creates a gestalt-like perceptual shift from exotic and primitive stereotypes to the familiarity of the Caribbean market. As such, alternative, carnivalesque understandings of the body emerge, highlighted by the grotesquely oversized breasts and backside of the design that festively bounce and gyrate in response to the performer's movements. These features also gesture to the potential for female agency, in the licensed time and space of carnival,

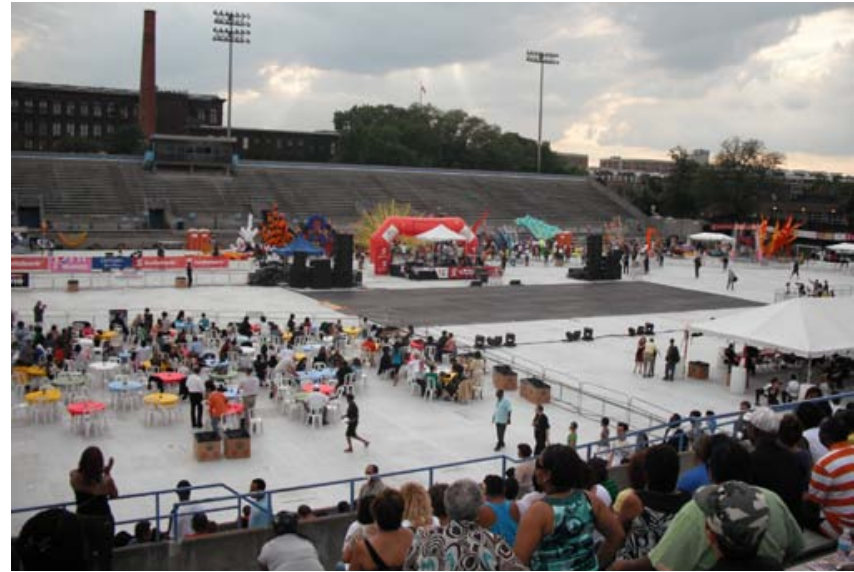

From the stands of Lamport Stadium watching the judging of the Mas for King and Queen. 29 June 2009.

Photo by Jacquey Taucar

to celebrate one's body and sexuality in a way that resists objectification. The costume activates the body in ways that return the audience's gaze via the breasts that also "look back" or the bottom that acts back, comically shaking and "mooning" the spectators. Mas costumes and their performativity illustrate how materiality and discourses operate interdependently, never separately.

\section{Writing the Mas and Its Performance- Another Reimagining}

There can never be a literal translation, for, as Linda Hutcheon points out, "transposition to another medium ... always means change: there are always going to be both gains and losses" (40). This article reimagines the embodied design process but can never represent the experience of making Mas. For Thea Jackson, the body knows through doing, and language often fails in explaining how the body knows, perhaps because the precise words for how the body negotiates the creative process do not yet exist. Mas making is a learned art that one experiences in a community setting at Mas camp through observation, apprenticeship, and practice with skilled Mas workers. The creative process of Mas making is an oral tradition, transmitted from one generation to the next, using the body as the site of knowledge. As such, Mas making does not have written documentation, thus opening a significant lacuna in the "official" record. While the embodied experience of Mas remains elusive, this discussion with Thea and Dario Jackson begins to fill the gaps in the archive.

\section{Notes}

1. Prior to 2011, the festival was known as Caribana but was forced to change its name due to litigation.

2. From masquerade, the masking or disguising of the self to perform alternative identities.

3. Few scholars study Caribbean-styled carnival costumes (see A. Ruth Tompsett, Lesley Ferris, and Milla Riggio).

4. "Play Mas" is the term for participants who dress in carnival costumes to celebrate and dance in the parade. 
5. Creating Mas involves many volunteers and hours to construct hundreds of costumes for players at different levels of embellishment (backline and frontline) and building the centerpieces of a band, the Big Mas costumes.

6. Unlike carnivals in Brazil or New Orleans, which showcase motorized floats.

\section{Works Cited}

Bettelheim, Judith. "Women in Masquerade and Performance." African Arts 31.2 (1998): 68-70 and 93-94. Print.

Cheng, Anne Anlin. Second Skin: Josephine Baker and the Modern Surface. Toronto: Oxford, 2011. Print.

Dalton, Karen, and Henry Louis Gates, Jr. "Josephine Baker and Paul Colin: African American Dance as Seen through Parisian Eyes." Critical Inquiry 24.4 (1998): 903-934. http:/ / dx.doi.org/10.1086/448901.

Espinet, Ramabai. “Caribana: A Diasporic Dub.” Fuse 22.1 (1999): 18-25. Print.

Ferris, Lesley, and Adela Ruth Tompsett. Midnight Robbers: The Artists of Notting Hill Carnival. London: Carnival Exhibition Group, 2007. Print.

Foster, Cecil. Caribana:The Greatest Celebration. Toronto: Ballantine Books, 1995. Print.

Freeman, Carla. "Is Local: Global as Feminine: Masculine? Rethinking the Gender of Globalization.” Signs 26.4 (2001): 1007-1037. http:/ / dx.doi.org/10.1086/495646.

Gallaugher, Annmarie. “Constructing Caribbean Culture in Toronto: The Representation of Caribana." The Reordering of Culture: Latin America, the Caribbean and Canada in the Hood. Eds. Alvina Ruprecht and Cecelia Taiana. Ottawa: U of Carleton P, 1995. 397-408. Print.

Houston, Lynne Marie. Food Culture in the Caribbean. Westport: Greenwood, 2005. Print.

Hutcheon, Linda. "From Page to Stage to Screen: The Age of Adaptation." Great Minds at the University of Toronto:The University Professor Lecture Series 2002-2003. Ed. Michael Goldberg. Toronto: U of Toronto P, 2003. 37-54. Print.

Jackson, Peter. "The Politics of the Streets: A Geography of Caribana." Political Geography 11.2 (1992): 130-151. http://dx.doi. org/10.1016/0962-6298(92)90045-U.

Jackson, Thea, and Dario Jackson. Personal interview. 20 Jan. 2012.

McKeown, Shane. "King \& Queen Competition at Lamport Stadium Thurs. Night.” CityNews.ca 28 July 2011. Web. 29 April 2011.

Philip, M. NourbeSe. A Genealogy of Resistance and Other Essays. Toronto: Mercury, 1997. Print.

Phillip, Lyndon. "The Caribana Festival: Continuity, Change, and an Alternative Music.” Diss. York University, 1998. Print.

Premdas, Ralph. "Diaspora and Its Discontents: A Caribbean Fragment in Toronto in Quest of Cultural Recognition and Political Empowerment." Ethnic and Racial Studies 27.4 (2004): 544-564. http: / /dx.doi.org/10.1080/01491987042000216708.

Tompsett, Adela Ruth. “'London Is the Place for Me': Performance and Identity in the Notting Hill Carnival.” Theatre History Studies 25 (2005): 43-60. Print.

Walcott, Rinaldo. "Caribbean Pop Culture in Canada; Or, the Impossibility of Belonging to the Nation.” Small Axe 9 (2001): 123-139. Print.

Jacqueline Taucar is a PhD candidate at the University of Toronto, Centre for Drama, Theatre, and Performance Studies. Currently she is completing her dissertation entitled "Acting Out(side) the Multicultural Script in Ethno-Cultural Festivals." As part of her doctoral study, Jacqueline has documented Toronto's Caribbean Carnival costumes and performances since 2007.

\section{Mas Camp Centre: Where the "Carnival Spirit" lives 365 days a year}

Out in an industrial park in north-east Scarborough, Anton Gabriel has created a vibrant showcase of Carnival costumes from Toronto and Trinidad's Carnivals. The Mas Camp Centre preserves a cultural tradition, archives the achievements of Band leaders and designers, and facilitates educational outreach programs. Gabriel often takes select costumes and objects from his collection to schools and organizes Mas workshops for students as well as loaning costumes from his collection for exhibits at the Royal Ontario Museum and other public displays. Now in its fifth year, the Mas Camp Centre grew from a personal collection of 10 pieces to now house approximately 600 costumes - the oldest dates back to the 1980 s - including beaded bikinis, elaborate headpieces, and backpacks, all of which have been donated by Mas players from Toronto and Trinidad. The Centre also has collectible items from Trinidad's world renowned band leaders and designers Peter Minshall and Brian MacFarlane. The Mas Camp Centre is more than just a repository for costumes, but rather a resource centre filled with videos, books, and magazines on Toronto and Trinidad's carnivals.

Mas Camp Centre: 120 Dynamic Drive, Unit 13, Scarborough; 416-524-1782.

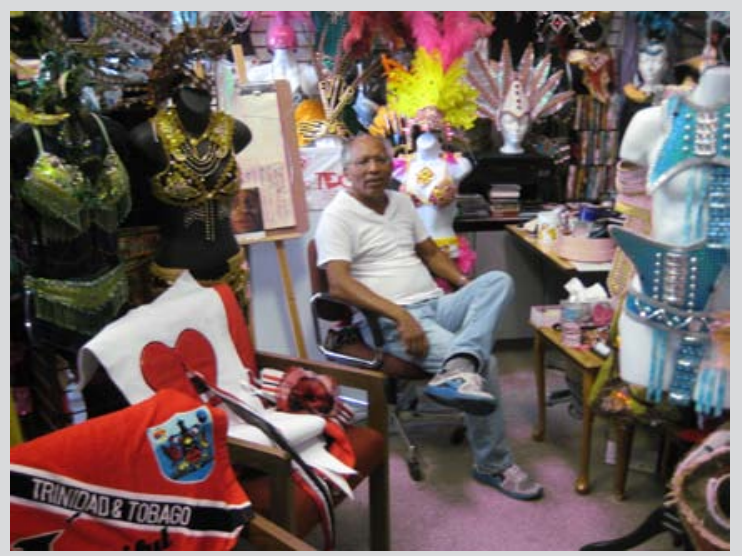

In the five years of its existence the Mas Camp Centre has accessioned approximately 600 costumes from Carnivals in Toronto and Trinidad and become an important resource. Seen here is founder and curator Anton Gabriel with a small sample of Carnival costumes in the collection. Photo courtesy of Anton Gabriel 